\title{
Rare Primary Lesion of the Costa: Hydatid Cyst
}

Hakan Demirtaşs ${ }^{1}$, Rasih Yazkan², Mustafa Kara' ${ }^{1}$, Ayşe Umul' ${ }^{1}$, Nilgün Şenol ${ }^{3}$ and Ahmet Orhan Çelik ${ }^{1}$

${ }^{1}$ Department of Radiology, Süleyman Demirel University, Turkey

${ }^{2}$ Department of Thoracic Surgery, Süleyman Demirel University, Turkey

${ }^{3}$ Department of Neurosurgery, Süleyman Demirel University, Turkey

Keywords: Hydatid cyst; Costa; Hydatidosis

\section{Description}

A 50-year old female patient, who had undergone hydatid cyst surgery of bilateral lung and liver, admitted to our hospital with the complaint of swelling and sensitization of the right lower thoracic region. No significant finding was found during her physical examination outside the described region, and biochemical blood tests are normal. Because of her history agglutination test was requested. It was $1 / 10240$ (positive test $>1 / 128$ ). A lesion containing septations, cystic areas and semisolid areas inside was detected at a depth of $3 \mathrm{~cm}$ from the skin during the ultrasound examination [US] performed for this region (Figure 1a). The patient was subjected to computed tomography [CT] and magnetic resonance imaging [MRI] in terms of relationship of these areas with surrounding tissues. A mass appearance in fluid density that caused significant destruction in ribs and extended to the surrounding soft tissues and the right paravertebral region was observed in the right 11 th and 12th ribs on the CT images (Figure 1b). A lesion containing a large number of cysts of hypointense in $\mathrm{T} 1$ sequences and hyperintense in $\mathrm{T} 2$ sequences in this region and showing a circumferential minimal contrast enhancement was observed on the MRI images (Figures 2a2c). The lesion was first thought to be hydatid cyst due to the current imaging findings and history. Surgery performed at Süleyman Demirel University Hospital, Isparta, Turkey in November 2015. Female vesicles in the cyst cavity were surgically evacuated first in a controlled manner. Then, the right 11 th and 12 th ribs were resected together with soft tissues (Figure 2d). After surgery, albendazole theraphy was continued for six months. $10 \mathrm{mg} / \mathrm{kg} /$ day dosage form was recommended as one week break of four weeks. Patient's symptoms were significantly decreased during follow-up. Also no pathological findings on physical examination.

Hydatid cyst is a parasitic disease caused by echinococcus cestode. It is known since the time of Hippocrates [1]. It is endemic in Mediterranean countries, Middle East, Far East, and South America, but it spreads around the world trough travels and migration. Turkey is among the countries where hydatid cyst is endemic with an incidence of $1 / 2000$ [2]. Organs which the disease most commonly involves are liver (52\% -77\%) and lung (10\%-40\%), respectively, and it can involve brain, kidney and the other organs, as well [2]. Costa involvement of hydatid

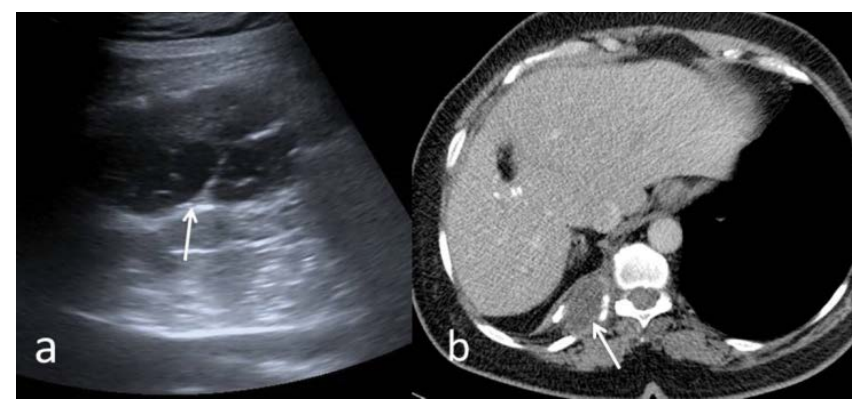

Figure 1: a) Lesion containing multiple cysts with semi-solid character on US scan and b) Lesion that infiltrated and destructed the ribs on the right paravertebral region and contained low-density $\mathrm{HU}$ values.

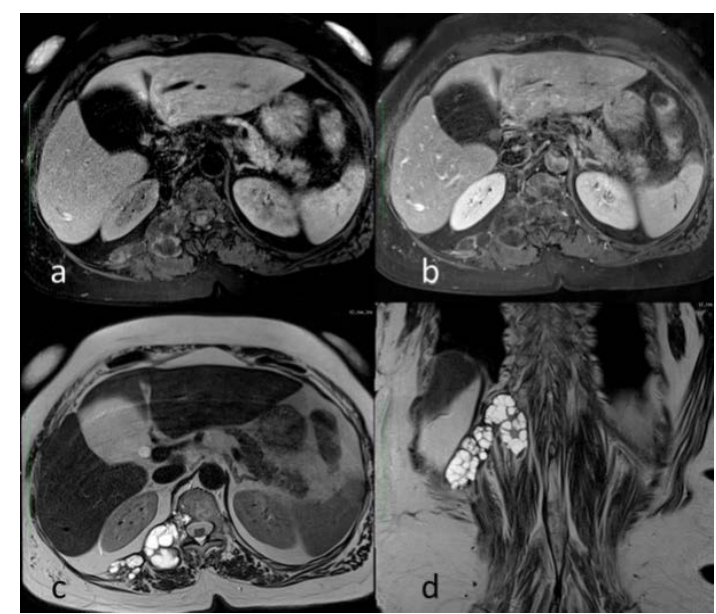

Figure 2: a) Hypointense multi-cystic lesion with a minimal circumferential involvement in the right paravertebral region in fat-suppressed T1 sequence and b) in fat-suppressed axial contrast-enhanced T1 sequence c) Hyperintense appearances of cysts involved the ribs and scattered surrounding regions in axial T2 sequence and d) coronal T2 sequence.

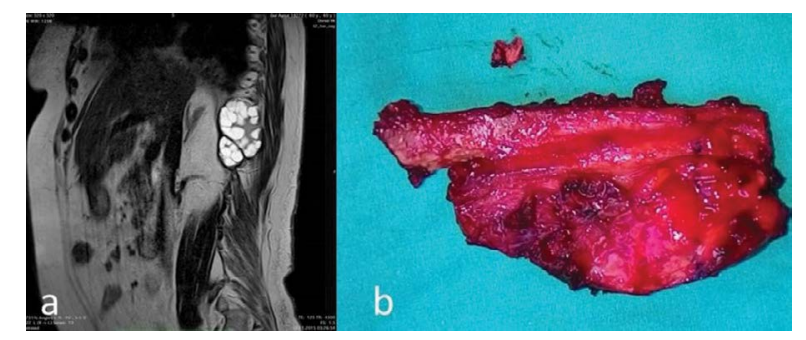

Figure 3: a) Appearance of the lesion in sagittal T2 sequence and b) Gross appearance of postoperative surgical specimen.

cyst in all cases is between $2 \%$ and $0.5 \%$. Involvement of ribs is very rare [2]. Hydatid cyst rib involvement shows infiltration to adjacent tissues by breaking down bone matrix as in our case [3]. Establishing the diagnosis of osseous hydatidosis first requires questioning of living conditions suspecting with radiological findings. MRI, CT and

*Corresponding author: Hakan Demirtaş, Department of Radiology, Suleyman Demirel University Hospital, Isparta, 32260, Turkey, Tel: +905058975010; Fax: +902462112830; E-mail: demhakan@yahoo.com

Received January 27, 2016; Accepted February 18, 2016; Published February 26, 2016

Citation: Demirtaş H, Yazkan R, Kara M Umul A, Şenol N, et al. (2016) Rare Primary Lesion of the Costa: Hydatid Cyst. Surgery Curr Res 6: 261. doi:10.4172/21611076.1000261

Copyright: (c) 2016 Demirtaş $\mathrm{H}$, et al. This is an open-access article distributed under the terms of the Creative Commons Attribution License, which permits unrestricted use, distribution, and reproduction in any medium, provided the original author and source are credited. 
Citation: Demirtaş H, Yazkan R, Kara M Umul A, Şenol N, et al. (2016) Rare Primary Lesion of the Costa: Hydatid Cyst. Surgery Curr Res 6: 261. doi:10.4172/2161-1076.1000261

US may be preferred as the imaging technique [2]. We have used all three examinations for diagnostic purposes. Although serological tests are helpful, definitive diagnosis requires surgery. Costal hydatid cyst generally has a slow course, and the results of the laboratory tests are frequently negative. However, in our patient, Indirect hemagglutination test for Echinococcus was positive and high (positive test $>1 / 128$ ). It has been reported that surgery and preoperative and postoperative albendazole therapy provide better outcomes [3]. Large doses over a long period of time would be a good clinical approach and may reduce the incidence of relapse. Because of liver toxicity intermittent therapy or monthly hepatic balance monitoring can preferred [3]. Our preference goes to surgery first followed by 6 months of postoperative prophylaxy by albendazole with intermittent therapy

\section{Teach Points}

- Although rare, hydatid cyst should be suspected in cystic lesions of the ribs.

- History and radiological findings are important in terms of leading to diagnosis.

- Definitive diagnosis and treatment of the disease requires surgery and combination therapy is very effective (surgery plus medical therapy).

\section{References}

1. Kılıç D, Cangır AK, Bulut Ş, Akay H (2003) Hydatid cyst of the rib with intramedullary involvement. Acta Chir Belg 103: 334-335.

2. Demir HA, Demir S, Emir S, Kacar A, Tiryaki T (2010) Primary hydatid cyst of the rib mimicking chest wall tumor: a case report. J Pediatr Surg 45: 2247-2249.

3. Chafik A, Benjelloun A, El Khadir A, El Barni R, Achour A, et al. (2009) Hydatid cyst of the rib: a new case and review of the literature. Case Rep Med 2009 817205 